\title{
Hotspots of unimproved sources of drinking water in Ethiopia: Mapping and Spatial analysis of Ethiopia Demographic and Health Survey Data 2016
}

Getahun Gebre Bogale ( $\sim$ getahungebre21@gmail.com )

Wollo University

Research article

Keywords: Ethiopia, Hotspot, Spatial, Unimproved, Water source

Posted Date: December 13th, 2019

DOl: https://doi.org/10.21203/rs.2.18991/v1

License: (c) (i) This work is licensed under a Creative Commons Attribution 4.0 International License.

Read Full License

Version of Record: A version of this preprint was published at BMC Public Health on June 8th, 2020. See the published version at https://doi.org/10.1186/s12889-020-08957-2. 


\section{Abstract}

Background: More than $35 \%$ of Ethiopian population is using drinking water from unimproved sources. As per the United Nations' Sustainable Development Goals, Ethiopia is aspiring to achieve universal and equitable access to safe and affordable drinking water for all by 2030. For these goals to be accomplished, it is important to map the country's hotspot areas of unimproved source of drinking-water so that resource allocation and disease control can be optimized there.

Methods: A population based cross-sectional study was conducted in Ethiopia from January 18 to June 27,2016 . Data were collected from 10,064 households using a pretested and structured questionnaire. A stratified two-stage cluster sampling was employed where the enumeration areas were primary sampling units and households were secondary sampling units. Systematic sampling with probability proportional to size was employed to select samples. Data were cleaned in spreadsheet and entered in to SaTScan and ArcGIS soft-wares for mapping and analysis. The Global Moran's I and spatial scan statistical tests (Bernoulli model) were done to explore the presence of clustering in the study area and local spatial clusters (hotspots) of unimproved sources of drinking water using ArcGIS version 10.3 and Kuldorff's SaTScan version 9.4 soft-wares, respectively. Moran's I value closer to +1 declared presence of clustering at national level and Log-Likelihood ratio (LLR) greater than the critical value with $p<0.05$ declared statistical significant hotspots across the regions.

Results: In this study, unimproved sources of drinking water were spatially clustered at the study area (Moran's l: $0.35, p<0.05$ ). A total of 143 significant clusters were identified. Of which, eight were most likely (primary) clusters and the rest 135 were secondary clusters. The first spatial window which contains primary clusters was located in Amhara and Afar regions (LLR: 78.89, at $p<0.001$ ). The rest 33 spatial windows which contain secondary clusters were found in all regions, except Gambela region and Addis Abeba city administration (with a range of LLR: 10.09-78.89, $p<0.001$ ).

Conclusions: This study identified non-random clusters and hot spots of unimproved sources of drinking water. Therefore, the result helps decision makers for their geographical interventions to combat problems related to hotspots.

\section{Background}

Unimproved drinking water source is one that by its nature the source does not properly protected from outside contamination, in particular with faecal matters [1]. World Health Organization (WHO) and WHO/UNICEF joint monitoring program categorized sources of drinking water as improved and unimproved. Improved sources of drinking water include piped water into dwelling, yard of plot, public tap or standpipe, tube-well or borehole, protected spring, protected dug well, and rainwater collection. On the other hand, unimproved sources of drinking water include unprotected well (dug); unprotected spring, cart with small tank or drum; tanker truck-provided water, surface water (river, dam, lake, pond, stream, canal, irrigation channel); bottled water (because of potential limits on the quantity of water available to a 
household through this source, not the quality) [2-5]. Worldwide, contaminated water from unimproved sources is the biggest killer of children[6].

Worldwide, 785 million people lack basic needs of water for drinking service which includes 144 million people who are still reliant on surface water (unimproved water source). More than two billion people are using a drinking water from unimproved sources (contaminated with faeces). Of this, the burden is more in sub-Saharan Africa countries. Consequently, people in these countries are vulnerable to water borne diseases. This contaminated drinking water is projected to cause 485,000 deaths due to diarrhea each year. By 2025 estimation, half of the world's population will be deemed to live in water-stressed settings [7].

A study done in Benin revealed that more than $49 \%$ of the households surveyed used unimproved water sources for their daily use [8]. In this study area, the majority of water with very high risk (68.7\%) was from unimproved sources of drinking water, particularly unguarded surface water and springs [5]. Surveys conducted at national level reported as 34 to 35 percent of households and $38.3 \%$ of population in the country using drinking water from unimproved sources [5, 9]. A study done in Dabat district, Ethiopia also reported that $51 \%$ of the respondents obtained their water from unimproved sources [10]. The time taken to collect water is greater for those using unimproved sources of water and for residents of rural areas, which is a double burden [5].

It is known that contaminated water can transmit diseases such as diarrhea, cholera, dysentery, typhoid, and polio which are caused by use of unsafe water from unimproved drinking water sources [7]. As expected, households who obtain their drinking water from improved sources are more satisfied with both water quality and availability than those who fetch it from unimproved sources [11]. Access to improved water sources significantly reduce water-borne diseases[12].

It is vital to have sustainable water sources for the health of human. Sustainable Development Goal (SDG) target 6.1 appeals for universal and equitable access to safe and affordable drinking water. The target is tracked by the indicator "safely managed drinking water services" which means drinking water should be accessed from an improved water source that is found on premises, available when needed, and free from any faecal and harmful chemical contaminants [7]. Ethiopia is planned to achieve this target by 2030 [13]. However, the nation is too far apart from the target.

Studies done in Nepal and sub-Saharan countries revealed that there were substantial geographical disparities of sources of drinking water $[12,13]$. Evidences on the spatial variation of unimproved sources of drinking water is still lacking at national level for geographical intervention. Therefore, to achieve the aspiring target and fill the gaps in information, it is important to explore the spatial patterns of unimproved sources of drinking water in Ethiopia and alert decision makers the specific administrative areas that are in greatest need of policy attention. So that resource allocation and disease control can be optimized. 


\section{Methods}

\section{Study setting}

This study was conducted in Ethiopia having a total population of 112, 469,180 million [14]. Ethiopia is located $3^{\circ}-14^{\circ} \mathrm{N}$ and $33^{\circ}-48^{\circ} \mathrm{E}$, at the eastern Horn of Africa. The country covers 1.1 million Sq. $\mathrm{km}$ and has a great geographical diversity, which ranges from 4,550 m above sea level (mountain Ras-Dashen) down to the Afar depression to $110 \mathrm{~m}$ below sea level (Dalol). There are nine regional states and two city administrations subdivided into 68 zones, 817 districts and 16,253 kebeles (lowest local administrative units of the country) in the administrative structure of the country $[9,15]$.

\section{Study design, period and population}

A population based cross-section design was employed to assess types of sources of drinking water among households from January 18 to June 27, 2016. The study populations were all Ethiopian people founded in the selected enumeration areas and households at the time of data collection $[9,15]$.

\section{Data source and measurement}

In every five years, the Ethiopian Demographic and Health Survey (EDHS) have collected data on national representative samples of key indicators including household drinking water supply. A stratified two-stage cluster sampling was employed where the enumeration areas (EA) were primary sampling units and households were secondary sampling units. An EA is a geographic area covering on average 181 households. In 645 EAs (202 urban and 443 rural areas), systematic random sampling with probability proportional to size was hired. A fixed number of 28 households per cluster were selected from households' sample frame. A structured and pretested questionnaire included household related variables towards sources of drinking water. Sources of drinking water were categorized by their type by asking the respondents that "what is the main source of drinking water for members of your household?" For this analysis, according to WHO classification, source of drinking water was categorized as "unimproved" and "improved". Location data were also taken from selected EAs. Both the survey and location datasets were accessed through the web page of International DHS Program [16]. After cleaning of the household dataset which does not have location data, 10,064 households/respondents from 621 EAs were included in this analysis.

\section{Data analysis}

The Global Moran's I and spatial scan statistical tests were done to explore the presence of clustering in the study area and local spatial clusters (hotspots) of unimproved sources of drinking water using ArcGIS version 10.3 [17] and Kuldorff's SaTScan version 9.4 [18] soft-wares, respectively. Global Moran's I statistic measures whether the patterns of unimproved sources of drinking water is dispersed, clustered or randomly distributed in the study area. Moran's I values close to -1 indicates unimproved sources of drinking water (UISDW) dispersed, whereas, Moran's I close to +1 and 0 indicate UISDW is clustered and 
distributed randomly, respectively. A statistically significant Moran's I $(p<0.05)$ value leads to rejection of the null hypothesis and indicates clustering of unimproved sources of drinking water $[15,19]$.

The spatial scan statistic uses a scanning window that moves across the study area. Households using unimproved sources of drinking water were taken as "Cases" and households using improved sources of drinking water were taken as "Controls" to fit the Bernoulli model. The maximum spatial cluster size of < $50 \%$ of the population at risk with a circle radius of $100 \mathrm{~km}$ was used, as an upper limit, which allowed both small and large clusters to be detected and ignored clusters that contained more than the maximum limit. For each potential cluster, a likelihood ratio test statistic was used to determine if the number of observed cases within the cluster were significantly higher than expected or not. The primary and secondary clusters were identified and assigned p-values and ranked based on their likelihood ratio test, on the basis of 999 Monte Carlo replications [15, 20, 21].

\section{Results}

Spatial epidemiology and patterns of unimproved sources of drinking water

The spatial distribution of unimproved sources of drinking water in Ethiopia was varied from region to region. As shown in the plot, there were variations in the number of sources per enumeration area. The number of unimproved sources of drinking water per enumeration area (cluster) were greater in Amhara region (particularly south and north Wollo, south Gondar, Waghemra, and East Gojam zones), the border areas of Tigray and Afar regions (eastern and southern Tigray and zone 2 of Afar), Southern nation and nationalities and peoples (SNNP) region (Keffa, Gamo Gofa, Konta, Dawro, and Bench Maji zones), Oromia region (southern part of Jimma zone), and Somali region (Fafan and Jarar areas) (Fig. 1).

The spatial pattern of unimproved sources of drinking water was non-random all over the study area. The Global Moran's I index was 0.11 which indicated that there was significant clustering of unimproved sources of drinking water in the country (Fig. 2).

Spatial scan statistical analysis of unimproved sources of drinking water

Based on purely spatial analysis scanning for clusters with high rates using the Bernoulli model, a total of 143 significant clusters were identified. Of which, eight were most likely (primary) clusters and the rest 135 were secondary clusters. The first spatial window which contains primary clusters was located in Amhara (eastern boarder of north shewa zone) and Afar (zone 3 and 4) regions. It was centered at $9.798697 \mathrm{~N}, 40.380059 \mathrm{E}$ with $55.24 \mathrm{~km}$ radius, with a relative risk (RR) of 2.23 and Log-Likelihood ratio (LLR) of 78.89, at $p<0.001$. Peoples living within the spatial window were 2.23 times higher risk of getting their drinking water from unimproved sources as compared to peoples living outside the spatial window (Additional file 1, Fig. 3)

The rest 33 spatial windows which contain secondary clusters were found in different regions. Of which, two of them found in Amhara region (north and south Gondar, and north and south Wollo zones); three in 
Somali region (Shebele, Afder, Jarar and Fafan); one in Hareri region; three in Afar region (zones of 1, 2, 4); three in Tigray region (north western, western and eastern zones); two in western and eastern boarder of Dire-Dawa; more than 9 in Oromia region (east and west Haregre, Bale, Arsi, Guji, south west Showa, Jimma, Kemashi, Kelem Welega zones); more than 5 in SNNP region (Keffa, Dawro, Konta, Hadya, Sheka, Segen peoples); and two in Gambela region (Nuer and Majang). An additional file shows this in more detail (Additional file 1, Fig. 3).

\section{Discussion}

This study shows that unimproved sources of drinking water at national and regional level are nonrandom. Significant hot spot areas of unimproved sources of drinking water were identified in eight regions and one city administration. In 2016 survey, the spatial scan statistics detected statistically significant clusters which could help programmers and policy makers to make appropriate decisions at regional level. Though there is lack of evidences as comparisons for this kind of study at local and national levels, this discussion was justified more of as per professional views. Of course, this finding, in agreement with another study, shows that the majority of rural households continued to rely on unimproved water sources [22].

In the first spatial window of primary clusters, $85 \%$ of households used their drinking water from unimproved sources. The hot spot areas were found in the junction area of the two regions (eastern Amhara and western Afar). It may be due to lack of attention given for peripheral and rural areas of the regions [11]. In other perspectives, the government and partners may not worry and give attention for population that may have available and accessible water sources, however, lack of quality. This idea is supported by national survey which stated that availability and sufficiency of drinking water, regardless of quality, is higher for unimproved sources of drinking water, and thus for rural areas [5].

The thirty three spatial windows that contain secondary clusters in different regions were found almost in peripheral areas of their respective regions and city administration. It is known that access of education is low in the border areas as compared to the central areas. If so, the less educated people may be less informed about how to protect their available sources and change to improved sources of drinking water. This is in line with a study done in sub-Saharan Africa [23].

The two spatial windows show hot spot areas of northern and north-east Amhara region. Like many subSahara African countries' rural areas, maintaining water source facilities, to keep its improved status, which often break and managing their operation of water sources in a sustainable way are still extremely challenging in rural areas of Amhara region. Most water source facilities in the region are under threat of losing functionality if the practice of operation and maintenance is not improved and changed to unimproved sources [24]. In other perspective, hot spots may happen due to problems in community perception about use of improved sources for drinking purpose is not good, which was agreed to study conducted in the region [25]. 
The three spatial windows include hot spot areas of Somali region may show that shortage of water in Somali region has devastated due to the ongoing multi-year drought. While climate resilient water source development is a key to mitigate negative impacts of the drought. Majority of the population in Somali region is still dependent on seasonal water harvesting ponds, which are categorized as unimproved sources of drinking water (UNICEF Ethiopia, 2017, The Government of Sweden grants US\$ 2.5 million to UNICEF for emergency response, unpublished). This phenomenon is similar for other regions like Afar; Gambela; boarder areas of SNNP, Oromia, Harari and Tigray regions; and rural and peripheral parts of Dire Dawa city administration[26]. Consequently, children living in hot spot areas are highly exposed to diarrheal diseases[27]. However, further investigation will be recommended to find the exact placement of unimproved sources of drinking water.

Limitations of the study

This study does not show exact location of unimproved sources of drinking water in the study area. Because the location data were taken from EAs (not from households/water sources) and the values were shifted $1-2 \mathrm{kms}$ for urban and $5 \mathrm{kms}$ for rural areas for data confidentiality issues. However, it indicated administrative areas where intervention will be needed.

\section{Conclusion}

This study identified non-random clusters and hot spots of unimproved sources of drinking water in different regions of the country. Though improvement was shown at national level, proportion of households using unimproved water sources are still high in the hot spot areas and still far apart from SDG and national goal. Therefore, priority attentions may be needed to hot spot areas for resource allocation and control of related diseases.

\section{Abbreviations}

EA:enumeration areas; EDHS:Ethiopia demographic and health survey; LRR:Log-likelihood ratio; RR:relative risk; SDG:Sustainable Development Goal; SNNP:Southern nation and nationalities and peoples; WHO:World Health Organization.

\section{Declarations}

\section{Ethics approval and consent to participate}

Ethical clearance with written consent was obtained from Measure DHS International Program which authorized the data-sets. All the data which used in this study are publicly available, aggregated secondary data with not having any personal identifying information that can be linked to particular individuals, communities, or study participants. Confidentiality of data maintained anonymously.

\section{Consent to publication}


Not applicable

\section{Availability of data and materials}

The data in which the author used to produce this manuscript are available and the author is prepared to share the customized dataset on request recognizing the benefits of such transparency. Otherwise, the original data-set can be accessed through www.dhsprogram.com after subscription and being an authorized user.

\section{Competing interests}

The author declares that there is no competing interest.

\section{Funding}

There was no any funding or sponsoring organization for this paper.

\section{Author's Contributions}

GG designed the study and develops the proposal, worked in data extraction, performed analysis and interpretation of the results and prepared the manuscript.

\section{Acknowledgments}

The author would like to thank The DHS Program for approving and providing the necessary datasets. My thanks also extended to my wife, Sr. Alemwork Desta, and Kids for their giving time space in doing this research.

\section{References}

1. Solution Finder. Unimproved Drinking Water Sources 2019 [cited 2019 14-Nov]. Available from: https://sswm.info/content/unimproved-drinking-water-sources.

2. World Health Organization. Drinking Water: The drinking water ladder. 2019.

3. Evans B, Bartram J, Hunter P, Williams AR, Geere J-A, Majuru B, et al. Public health and social benefits of at-house water supplies. University of Leads: Leeds, UK. 2013:1-61.

4. Onda K, LoBuglio J, Bartram J. Global access to safe water: accounting for water quality and the resulting impact on MDG progress. International journal of environmental research and public health. 2012;9(3):880-94.

5. Central Statistical Agency of Ethiopia. Drinking Water Quality in Ethiopia: Results from the 2016 Ethiopia Socioeconomic Survey. 2017.

6. Watkins K. Human Development Report: Power, Poverty and the Global Water Crisis. Heliyon. 2006:e00931. 
7. World Health Organization. Drinking-water: Key facts: WHO; 2019 [cited 2019 August 14]. Available from: https://www.who.int/news-room/fact-sheets/detail/drinking-water

8. Johnson RC, Boni G, Barogui Y, Sopoh GE, Houndonougbo M, Anagonou E, et al. Assessment of water, sanitation, and hygiene practices and associated factors in a Buruli ulcer endemic district in Benin (West Africa). BMC public health. 2015;15(1):801.

9. Central Statistical Agency (CSA) [Ethiopia], ICF. Ethiopia Demographic and Health Survey 2016. Addis Ababa, Ethiopia, and Rockville, Maryland, USA: CSA and ICF; 2016.

10. Bitew BD, Gete YK, Biks GA, Adafrie TT. Knowledge, Attitude, and Practice of Mothers/Caregivers on Household Water Treatment Methods in Northwest Ethiopia: A Community-Based Cross-Sectional Study. The American journal of tropical medicine and hygiene. 2017;97(3):914-22.

11. Abebaw D, Tadesse F, Mogues T. Access to improved water source and satisfaction with services: Evidence from rural Ethiopia. International Food Policy Research Institute (IFPRI); 2010.

12. Pullan RL, Freeman MC, Gething PW, Brooker SJ. Geographical inequalities in use of improved drinking water supply and sanitation across sub-Saharan Africa: mapping and spatial analysis of cross-sectional survey data. PLoS medicine. 2014;11(4):e1001626.

13. He W-J, Lai Y-S, Karmacharya BM, Dai B-F, Hao Y-T, Xu DR. Geographical heterogeneity and inequality of access to improved drinking water supply and sanitation in Nepal. International journal for equity in health. 2018;17(1):40.

14. World Population Review. Ethiopia Population 2019. 2019 [cited 2019 August 19 ]. Available from: http://worldpopulationreview.com/countries/ethiopia-population/.

15. Bogale GG, Gelaye KA, Degefie DT, Gelaw YA. Spatial patterns of childhood diarrhea in Ethiopia: data from Ethiopian demographic and health surveys (2000, 2005, and 2011). BMC infectious diseases. 2017;17(1):426.

16. ICF. The DHS Program: Demographic and Health Surveys 2019 [cited 2019 14-Nov]. Available from: https://dhsprogram.com/

17. Desktop EA. Version 10.3. Redlands CA: Environmental Systems Research Institute. 2014.

18. Kulldorff M. SatScan Software for spatial, temporal and space-time scan statistics (version 9.4. 2) [software]. Recuperado de http://www satscan org. 2011.

19. Zulu LC, Kalipeni E, Johannes E. Analyzing spatial clustering and the spatiotemporal nature and trends of HIV/AIDS prevalence using GIS: the case of Malawi, 1994-2010. BMC infectious diseases. 2014;14(1):285.

20. Kulldorff M. SaTScan user guide for version 9.4. 2015. 2017.

21. Alemu K, Worku A, Berhane Y, Kumie A. Spatiotemporal clusters of malaria cases at village level, northwest Ethiopia. Malaria journal. 2014;13(1):223.

22. Seyoum S, Graham JP. Equity in access to water supply and sanitation in Ethiopia: An analysis of EDHS data (2000-2011). Journal of Water, Sanitation and Hygiene for Development. 2016;6(2):32030. 
23. Armah FA, Ekumah B, Yawson DO, Odoi JO, Afitiri A-R, Nyieku FE. Access to improved water and sanitation in sub-Saharan Africa in a quarter century. Heliyon. 2018;4(11):e00931.

24. Tilahun SA, Collick AS, Ayele M. Assessment of Water Supply and Sanitation in Amhara Region. 2012.

25. Beyene HA. Factors affecting the sustainability of rural water supply systems: The case of Mecha Woreda, Amhara region, Ethiopia: Citeseer; 2012.

26. WASH Cluster Ethiopia. WASH CLUSTER BULLETIN: ETHIOPIA HUMANITARIAN RESPONSE 2017: CLIMATE RESILIENT WATER SUPPLY SYSTEMS IN ARID AND SEMI-ARID REGIONS OF ETHIOPIAMOWIE. Addis Abeba: Ministry of Water Irrigation and Electricity, Ethiopia; 2017.

27. Azage M, Kumie A, Worku A, Bagtzoglou AC. Childhood diarrhea in high and low hotspot districts of Amhara Region, northwest Ethiopia: a multilevel modeling. Journal of health, population and nutrition. 2016;35(1):13.

\section{Figures}

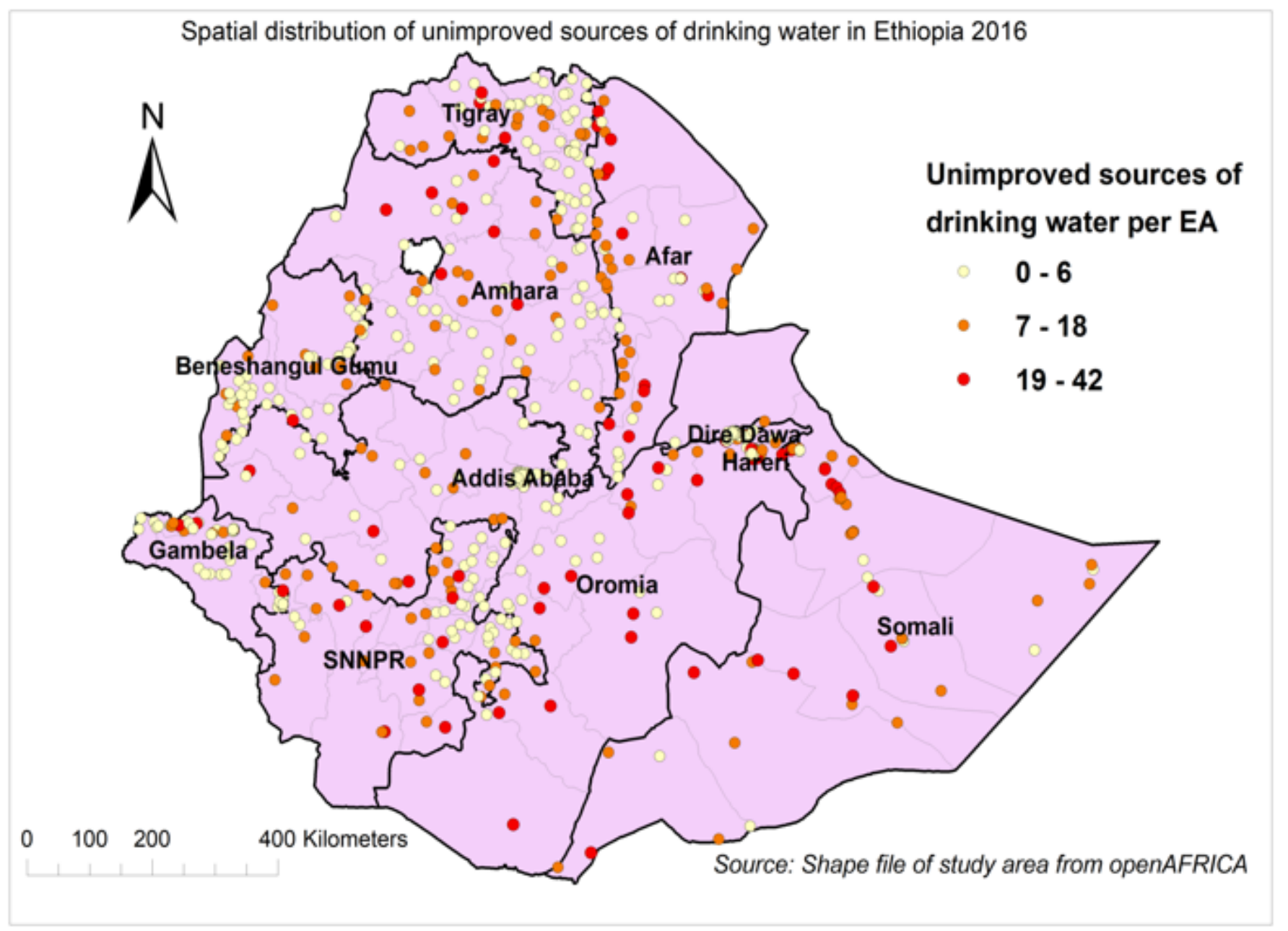

Figure 1 
Spatial distribution of unimproved sources of drinking water in Ethiopia, EDHS 2016. Each spot (point data) on the plot represents one EA which encompasses the number of unimproved sources of drinking water (cases). The red color spots indicate areas with high rates of cases.

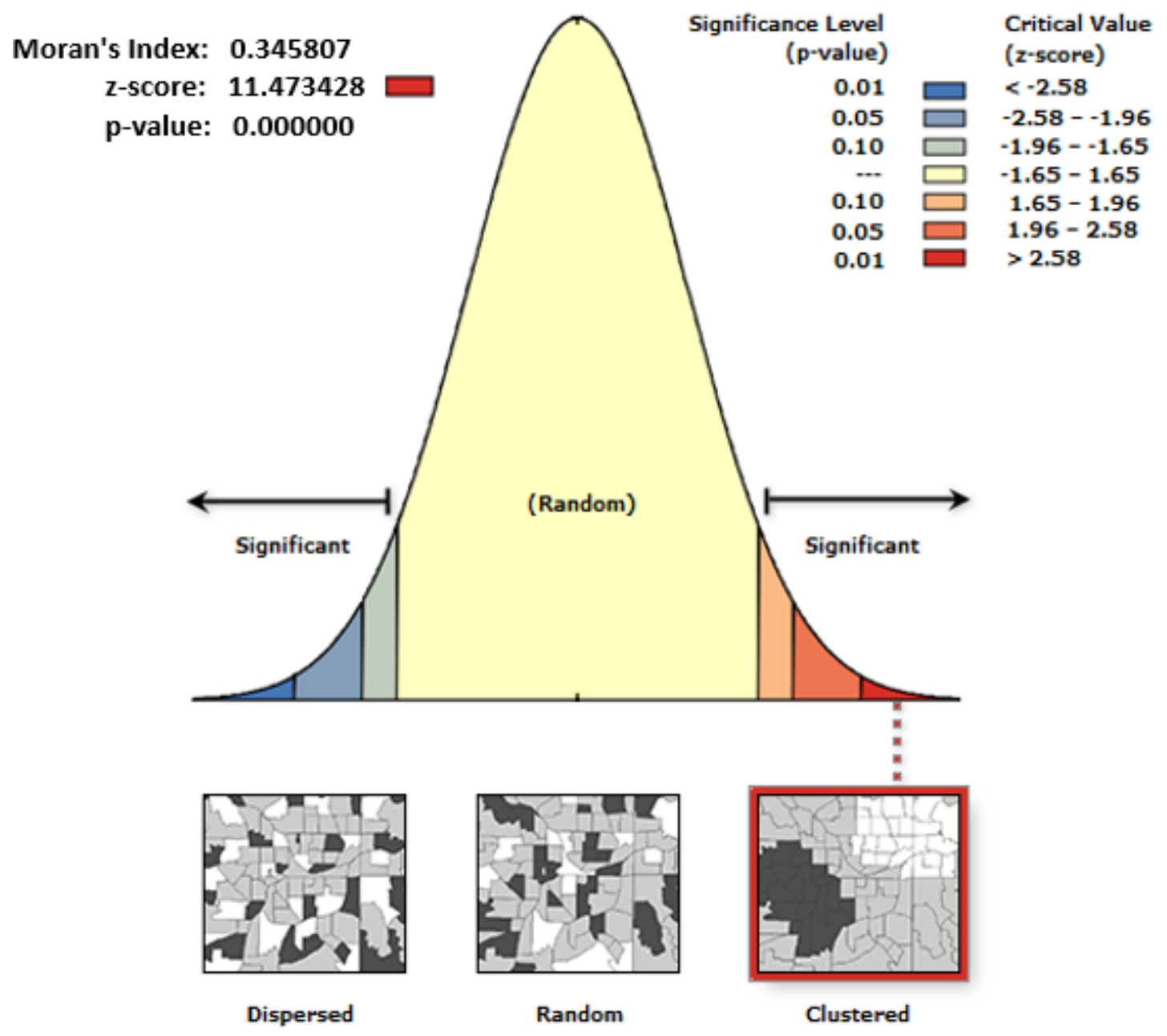

Figure 2

Spatial patterns of unimproved sources of drinking water in Ethiopia, EDHS 2016. The cluster pattern on the right side shows high rates of cases occurred over the study area. The output has automatically generated keys on the right and left top sides of the plot. An auto-generated interpretation shows that the likelihood of clustered pattern occurred by random chance is less than one percent. The bright red and blue colors to the end tails of the plot indicates increased significance level. 


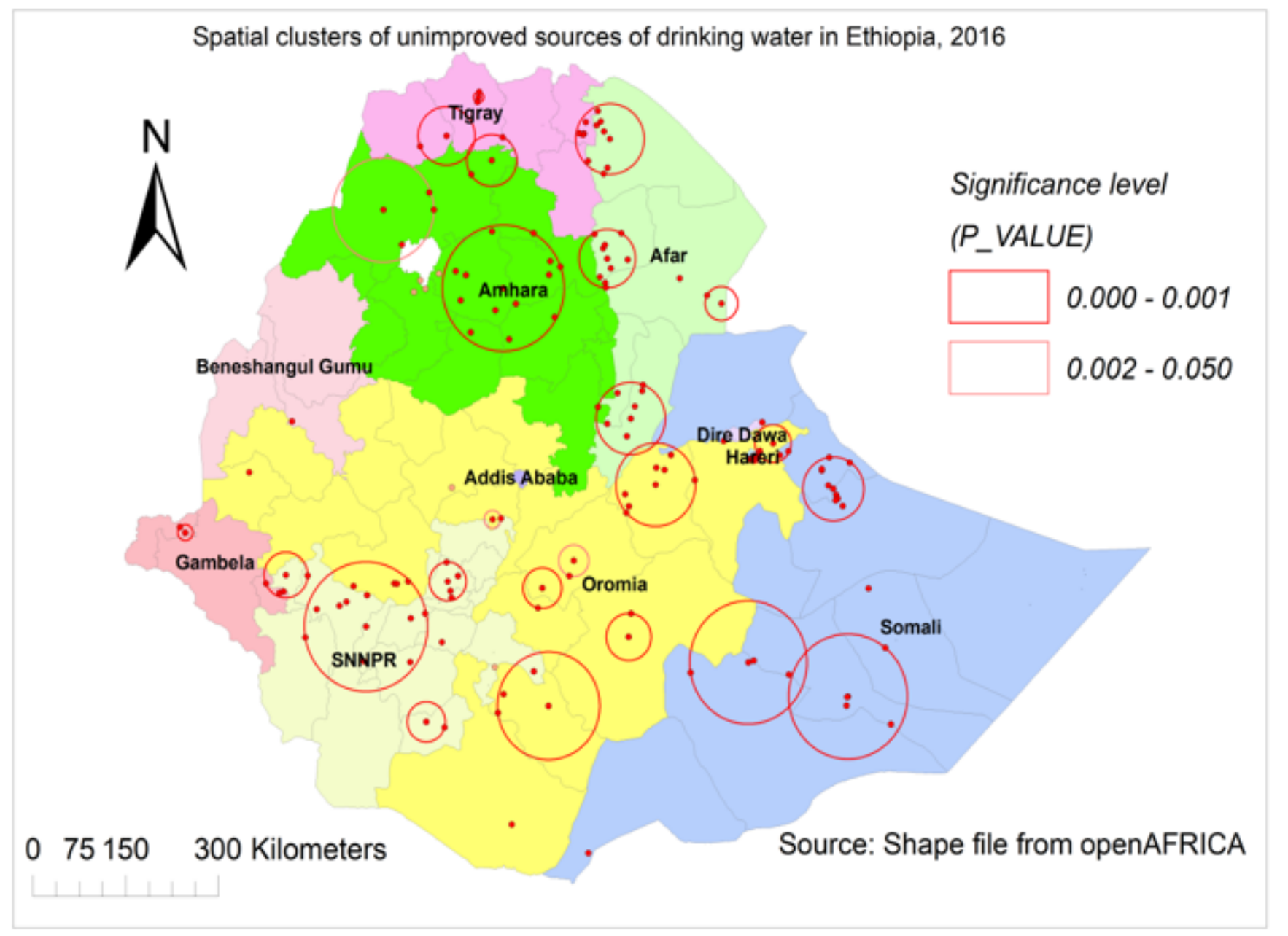

\section{Figure 3}

Most likely and secondary clusters of unimproved sources of drinking water in Ethiopia, EDHS 2016. The bright red color rings indicate the most statistically significant spatial windows which contain primary and secondary clusters of unimproved sources of drinking water. Interpretation: Household members within the spatial window are at higher risk of getting their drinking water from unimproved sources than families outside the spatial window.

\section{Supplementary Files}

This is a list of supplementary files associated with this preprint. Click to download.

- Additionalfile1.docx 